Instructions for authors, subscriptions and further details:

http://brac.hipatiapress.com

\title{
Errare Est... Aproximaciones Indisciplinares en las Prácticas Artísticas Contemporáneas
}

Eloi Puig Mestres, Victor Manuel Ornelas Magalháes ${ }^{1}$

1) University of Barcelona (Spain), University of Madeira. (Portugal)

Date of publication: October $3^{\text {rd }}, 2018$

Edition period: October 2018 - February 2019

To cite this article: Puig, E., Ornelas, V. M. (2018). Errare Est...

Aproximaciones Indisciplinares en las Prácticas Artísticas Contemporáneas. Barcelona, Research, Art, Creation, 6(3) 271-295. doi: 10.17583/brac.2018. 3046

To link this article: http://dx.doi.org/10.17583/brac.2018.3046

\section{PLEASE SCROLL DOWN FOR ARTICLE}

The terms and conditions of use are related to the Open Journal System and to Creative Commons Attribution License (CC-BY) 
BRAC - Barcelona Research Art Creation. Vol. 6 No. 3, October 2018, pp. 271-295

\section{Errare Est... Indisdiplinary Approaches in Artistics Contemporary Practices}

Eloi Puig Mestres, Victor Manuel Ornelas Magalháes

1) University of Barcelona (Spain), University of Madeira. (Portugal)

(Received: 24 October 2017; Accepted: 19 June 2018; Published: 3 October 2018)

\section{Abstract}

Errors, noise, accidents, interruptions, saturation, chaos, disorder are often related to the results of questioning, just as they are difficult words that we quickly identify as pejorative, which we do not understand or expect, what we despise. Many artists refer to the world as human excretion, virus, vomit, sterile, within the limits of institutional and governmental power. This article aims to approach some artistic practices that have, under a perspective of questioning the status quo of the system, dealt with the multiform of what we have often called error.

Keywords: error, noise, serendipity, resignification, interference, randomness, negation 
BRAC - Barcelona Research Art Creation. Vol. 6 No. 3, October 2018, pp. 271-295

\section{Errare Est... Aproximaciones Indisciplinares en las Prácticas Artísticas Contemporáneas}

Eloi Puig Mestres, Victor Manuel Ornelas Magalháes

1) University of Barcelona (Spain), University of Madeira. (Portugal)

(Recibido: 24 octubre 2017; Aceptado: 19 junio 2018; Publicado: 3 octubre 2018)

\section{Resumen}

Los errores, el ruido, los accidentes, las interrupciones, la saturación, el caos, el desorden son a menudo relacionados con los resultados de interrogantes, de la misma manera son palabras difíciles que rápidamente identificamos insertadas hacia a lo peyorativo, lo que no entendemos ni esperamos, lo que despreciamos porque nos es ajeno. Muchos artistas nos referencian el mundo como excrecencia humana, virus, vómito, estéril, en los límites del poder institucional y gubernamental. Este artículo pretende ser una aproximación a algunas prácticas artísticas que han abordado, bajo una perspectiva de cuestionamiento del status quo del sistema, lo multiforme de aquello que a menudo hemos llamado error.

Palabras clave: error, ruido, serendipia, resignificación, interferencia, azar, negación 
El hombre es un animal que se contradice. Se contradice y contradice (...) en el sentido de un verdadero y propio vértice de suprema conciencia teórica negativa y por ello de un pensamiento que niega y niega universalmente. (Formaggio, 1976, p. 91)

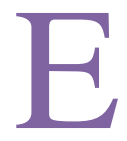

sto es lo que escribía en 1973, de manera minuciosa, Dino Formaggio en su libro Arte. Aparece en el capítulo "El Arte bajo el signo de la nada" y nos ayuda a introducir la relación existente entre arte, contradicción, negación y error. Estas cuatro palabras son los conceptos que quiere desarrollar nuestra proposición. Como estos conceptos se debaten constantemente en la producción artística y ayudan a enfatizar el propio proceso creativo como lugar de experimentación próximo e inherente al error.

Cojamos la frase tantas veces citada y utilizada de Samuel Beckett. "Ever tried. Ever Failed. No matter. Try again. Fail again. Fail better" (Beckett, 2001). Admitir el error. Admitir el fracaso. De este modo es posible contrariar el efecto negativo del error, del azar o del fracaso. La dupla de artistas Fischli \& Weiss manifiestan de forma muy concisa y escueta en su decálogo How to Work Better (reproducido en Le Feuvre, 2010, p. 145).

1. DO ONE THING AT A TIME

2. KNOW THE PROBLEM

3. LEARN TO LISTEN

4. LEARN TO ASK QUESTIONS

5. DISTINGUISH SENSE FROM NONSENSE

6. ACCEPT CHANGE AS INEVITABLE

7. ADMIT MISTAKES

8. SAY IT SIMPLE

9. BE CALM

10. SMILE

(Peter Fischli \& David Weiss, 1999/2000, printing text).

Diez designios adaptables a cualquier contexto de trabajo o a cualquier contexto creativo. Diez afirmaciones que rozan lo ridículo por ser tan evidentes. ADMIT MISTAKES. Estar abierto al error y a sus consecuencias, derivaciones o imprevistos, es abrirse a lo inestable, lo contingente, lo imprevisible. Si bien que el devenir representa lo incierto, en el contexto artístico, no obstante, se trata de una incerteza controlada (por lo menos parte del proceso lo es) y en la mayor parte de los casos intencional o 
provocada. Algo que genera una tensión que eleva el objeto artístico a una suspensión movediza y desnaturaliza la negación. Aceptar y convertir lo adverso en potencia creadora y en metodología activa (como en el caso paradigmático presente en el corpus de la obra de Fischli \& Weiss).

Esto nos sirve para balizar un territorio en el cual un conjunto de metodologías y prácticas artísticas logran establecer una contra-negación a partir de los fenómenos de ruido, saturación, desorden, caos, error aleatorio y lo accidental. Lo desechable o indeseable (incluso lo políticamente incorrecto) se vuelve la piel renovada de propuestas que reaccionan al desprecio por el error y reanudan vínculos insospechados.

Errare humanum es una expresión que no hace más que sumarse al argumentario de nuestro vínculo natural con el error. Literalmente significa "Errar es humano" usada por considerar que el equivocarse es intrínseco a la naturaleza humana, por lo que hay que aceptar los errores, y aprender de ellos para evitar que se repitan. La frase ha entrado en el lenguaje común, como aforismo con el que se busca mitigar un fallo, siempre que sea esporádico y no se repita. La expresión latina completa es: errare humanum est, sed perseverare diabolicum; que traducida literalmente significa: "errar es humano, pero perseverar (en el error) es diabólico."

"Fail again, fail better" propone precisamente aceptar el cambio y el error como el principio de inevitabilidad de la naturaleza humana. Errare humanum est pero también Errare machina est. Los sistemas informáticos están organizados para eliminar el error pese a que la programación no es infalible y los hackers bien lo saben que las brechas existen y qué hacer con ellas. Como las brechas en los discursos (Roland Barthes o Umberto Eco y otros autores más recientes han sabido identificar) el lenguaje es también un virus (como lo entendía William Burroughs), una máquina procesual y digerible y como tal sujeta a variables, alteraciones, cambios de percepción, que han, a lo largo del siglo XX, atraído a artistas de variopinto origen.

También el cine ha buscado escenarios en las que el error de la máquina supone un orden más allá de sus límites, hacia una máquina pensante. Recordemos un diálogo de la película 2001. Odisea en el espacio de Stanley Kubrick:

La voz del ojo mecánico rojo Hall sospecha...

HAL: - En las últimas semanas me he preguntado si ustedes no tendrían otra idea acerca de la misión

Dave: - ¿Qué quieres decir?

HAL: - Pues, no es fácil de concretar. Quizá no hago más que expresar mis propias preocupaciones [..] Nunca me he liberado 
completamente de la sospecha de que hay algunas cosas muy extrañas en esta misión [...] El caso es que nadie podía ignorar las extrañas historias que circulaban por allí antes de que partiéramos. Rumores de que se habían hecho ciertas excavaciones en la Luna.

La conversación entre David Bowman y la supercomputadora HAL 9000 evidencia la preocupación de la máquina y cómo ésta comienza a mostrarse crítica con la misión. Y es aquí cuando HAL se hace completamente humano, cuando simula una avería. Como no obtiene ninguna respuesta por parte de Bowman a su preocupación, decide actuar por su cuenta. Su auto interrupción para anunciar un fallo en una unidad de comunicaciones, con la consecuente pérdida de conexión con la Tierra, es la semilla que generará los conocidos diálogos de rivalidad entre la computadora y Bowman. Una rivalidad que conllevará incluso la muerte de uno de los tripulantes y desembocará finalmente en los episodios de delirio del gran superordenador de la nave espacial. La suspicacia de un error provoca un desenlace agonizante. Esta cadena de errores y sus consecuencias funcionan como gran metáfora de la existencia del error, de la necesidad de tener en cuenta la presencia de lo imprevisto, del desajuste, de la contradicción, en definitiva, del error.

\section{Perspectivas del Error}

La resignificación, el error procesual, y la saturación sensorial son tres aspectos que pueden funcionar como argumentarios bajo los que detectamos la aparición del error, de la interrupción, de la interferencia. Todos ellos son motivos que pueden adquirir múltiples formas expresivas, tanto en el espacio pictórico, como en el espacio escultórico, en la instalación, en el ámbito sonoro, etc.

\section{Resignificación}

El arte contemporáneo busca resignificar los conceptos de arte ya existentes ya que el artista se da cuenta que no puede seguir siempre la estela del camino marcado, no puede seguir creando más arte, sino que, en vez de eso, debe dar una nueva interpretación. En este proceso de resignificación se encuentra la negación y oposición a los preceptos establecidos. Podemos, pues, identificar el error o el ruido como partes integrantes de la forma de operar propia del arte, es decir, como parte intrínseca a esta. Un ejemplo que 
puede mostrar este trabajo de resignificación lo encontramos en el contexto de los fotomontajes del artista conceptual inglés John Stezaker (UK, 1949). Su trabajo se basa en la reutilización de imágenes de otros autores, postales, fotografías de revistas o de libros, con las que realiza múltiples series de collages. Desde los años 70, a través de la yuxtaposición del contenido y el contexto de las imágenes originales busca transmitir sus propios significados, con un sutil sentido de humor y cierta calidad nostálgica. Mientras que muchas de sus obras están creadas con el tradicional método del "cortar y pegar", otras consisten simplemente en el reencuadre de una imagen preexistente, con resultados provocadores.

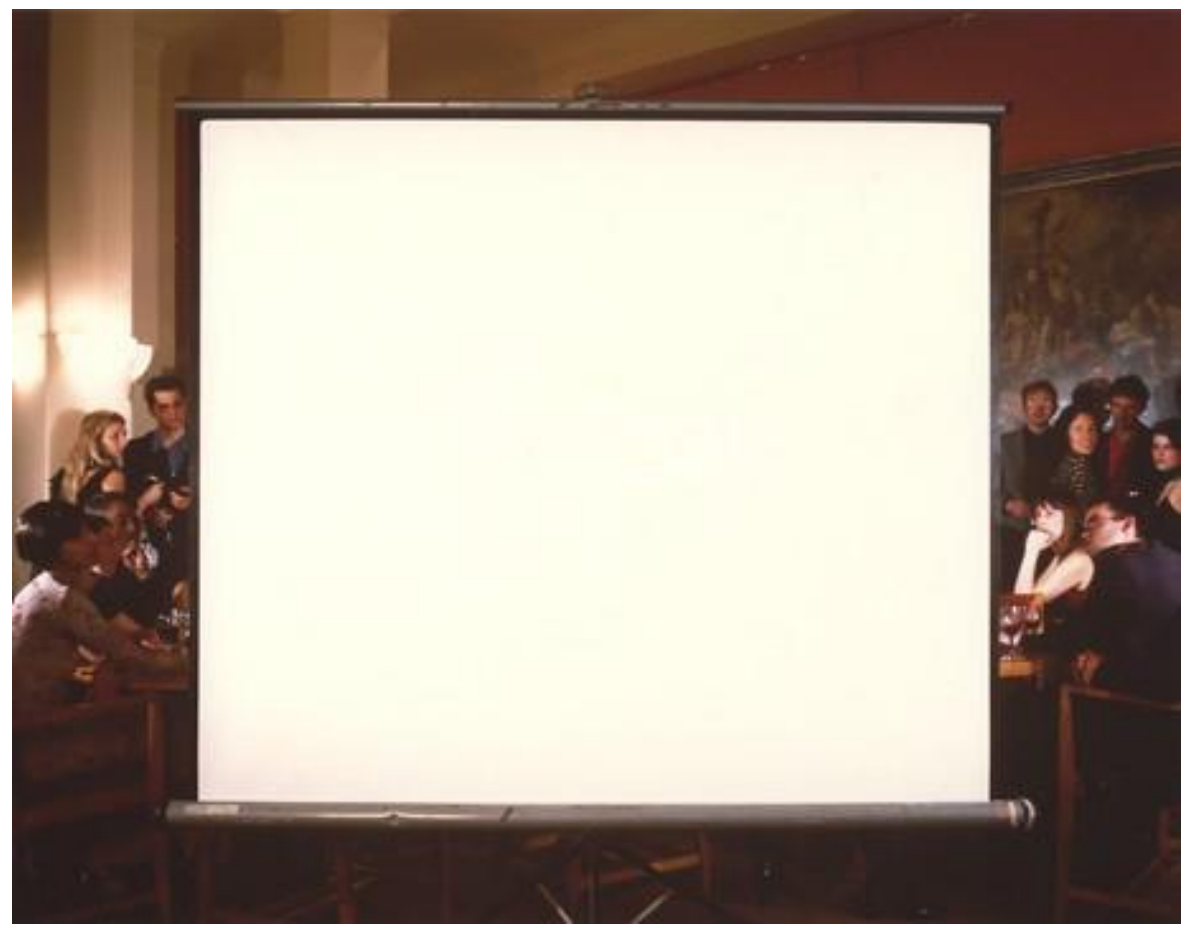

Imagen 1. John Hilliard. 1999. Off Screen (3), large study. Cibachrome on museum board. 78 x $93 \mathrm{~cm}$. Recuperado desde https://artlogic-res.cloudinary.com/w_460,h_360,c_fill,f_auto,fl_lossy/wsrichardsaltoun/usr/images/exhibitions/group_images_override/36/hilliard2.jpg

Stezaker comparte con otros artistas, sus contemporáneos, el interés por la obstrucción visual, siguiendo una pauta de interrupción: John Hilliard, veterano artista conceptual británico, que trabaja predominantemente con la fotografía. Sus obras más recientes, a partir de los noventa, construyen un 
espacio visual en el que la imagen dentro de la imagen (mise en abyme) no pretende ampliar el efecto ilusorio de profundidad, o simplemente crear un cuadro dentro de otro, sino una obstrucción de la percepción. Entre lo teatral y lo conceptual, las imágenes de Hilliard son una especie de ensayos fotográficos en los que el artista coloca en la arena espectador e imagen, la fotografía como representación de lo real y como construcción visual de una realidad o como espacio de auto-reflexividad. Ejemplos como Off Screen (3), large study, de 1999 o Debate (18\% Reflectance) $N^{\circ} 1$, de 1996, manifiestan preocupaciones con el plano de representación en el cual la fotografía incita a una dialéctica de circuncisión: deja caer el velo que prende la imagen para descubrir otro delicado obstáculo.

Una de las series más conocidas de John Stezaker, Tabula Rasa, pone en evidencia los vacíos, la ausencia en la imagen, dejando al espectador el trabajo de asociar otras imágenes, otras posibilidades de imágenes. Podríamos ofrecer otros ejemplos como los del artista francés Pierre Bismuth, con una obra que indaga sobre los límites de lo visual (como podemos apreciar en la serie Following the right hand); o los del norteamericano John Baldessari, con sus habituales círculos de colores que anulan y marcan zonas de las reproducciones de fotografías de revistas o de fotogramas de películas. Estos obstáculos visuales son objetos de una mirada que invita a una resignificación, a una reflexión inusual de lo habitual. Nos colocan en un plano necesariamente fuera de la imagen. En un lugar en negativo.

Otros artistas-fotógrafos han explorado el error fotográfico como dispositivo conceptual sobre la naturaleza ambigua de la fotografía. Encontramos un claro ejemplo de ello en la obra de José Luís Neto. Ampliando y reencuadrando detalles de imágenes apropiadas de archivos, Neto les atribuye un nuevo sentido y otra mirada. En la serie Anónimos (2005) los fallos, que se deben a desenfoques, zonas rayadas o por razones de velocidad de captación, convierten los transeúntes de la ciudad de Lisboa (de donde proceden las imágenes originales) en manchas difusas, en fragmentos ciegos olvidados por la cámara. Son residuos de realidades en los márgenes de visibilidad, que han quedado abandonados pero que, en este contexto, se les asigna un papel protagonista, pese a que sean imágenes insuficientes desde el punto de vista de la información visual. Sin embargo, es justamente este aspecto incompleto, frágil y borroso lo que les da una fuerza conmovedora. Neto trabaja a menudo a partir de archivos oficiales (por ejemplo, el Archivo Municipal de Lisboa, para el caso concreto de la referida serie) o a partir de imágenes encontradas por casualidad y que 
permiten construir una narrativa paralela, como en el caso del proyecto PMC/P.M.I. Passport (2008). En consecuencia, a las imágenes se les ofrece un nuevo ropaje y un dominio conscientemente enigmático a ocupar.

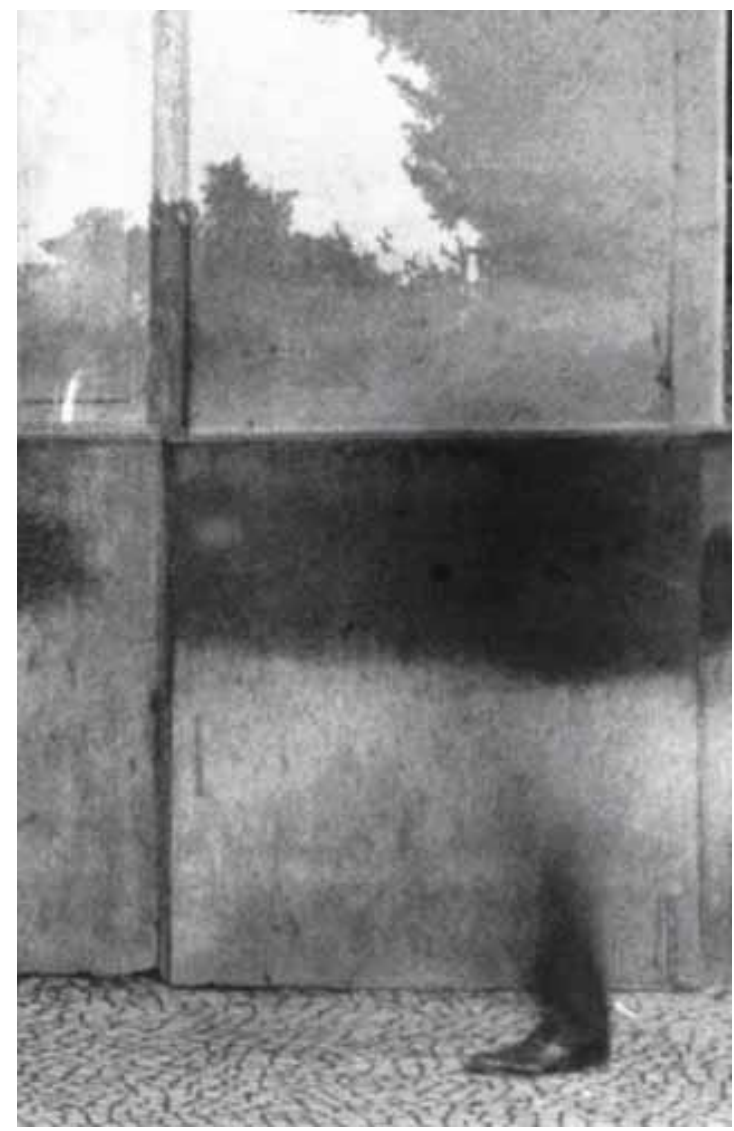

Imagen 2. José Luís Neto. 2005. De la serie Anónimo. Prueba, gelatina de plata. 7,1 x 4,6 cm. Recuperada desde http://www.miguelnabinho.com/popupobras.php $\underline{\text { ?art }=18 \& \text { folio }=19}$

Por otra parte, en el ámbito sonoro figuras "turntablistas" como Christian Marclay (Turntablist, 1983), Otomo Yosihide (Ground Zero, 1993) o Martin Tétreault (Catoon, 1999) dedicados a manipular vinilos recuperados para generar nuevas lecturas, ejemplificando la reapropiación y recomposición. Estas tres figuras son expertos en el remezcla de vinilos que sufren todo tipo 
de transformaciones, agujeros, objetos adheridos, pliegues, múltiples rizos de diferentes materiales para originar ruidos desordenados producidos por la aguja en contacto. Procesos indisciplinares que desmontan el uso original de un material inicialmente frágil para generar nuevos contextos de gramáticas difícil de descifrar. Los accidentes son dotados de interés ya que activan cambios evolutivos en los objetos, se integran en un estudio metalingüístico ya que se reivindican como generados por máquinas que hablan de la máquina que los generan. Igualmente, no podemos pasar por alto el siempre presente en cualquier aportación experimental en el ámbito sonoro la figura de John Cage, cuando ya en 1968 compuso la pieza 33 1/3, un tipo de instalación de sonido participativo en el que 24 giradiscos con altavoces estéreo y casi 300 vinilos fueron colocados alrededor de una habitación sin sillas. En esta instalación la audiencia que entra en la habitación no obtiene ninguna instrucción y es libre de poner los vinilos para manipularlos en el fonógrafo. El resultado es una multi-amalgama de diferentes fuentes sonoras simultáneas lejos de cualquier reminiscencia armónica, totalmente ruidística insertada en el puro estilo cagiano. El autor rompe las barreras entre público y artista, entre el sonido y la música, requiriendo únicamente de una audiencia-participante con oído abierto y mente curiosa.

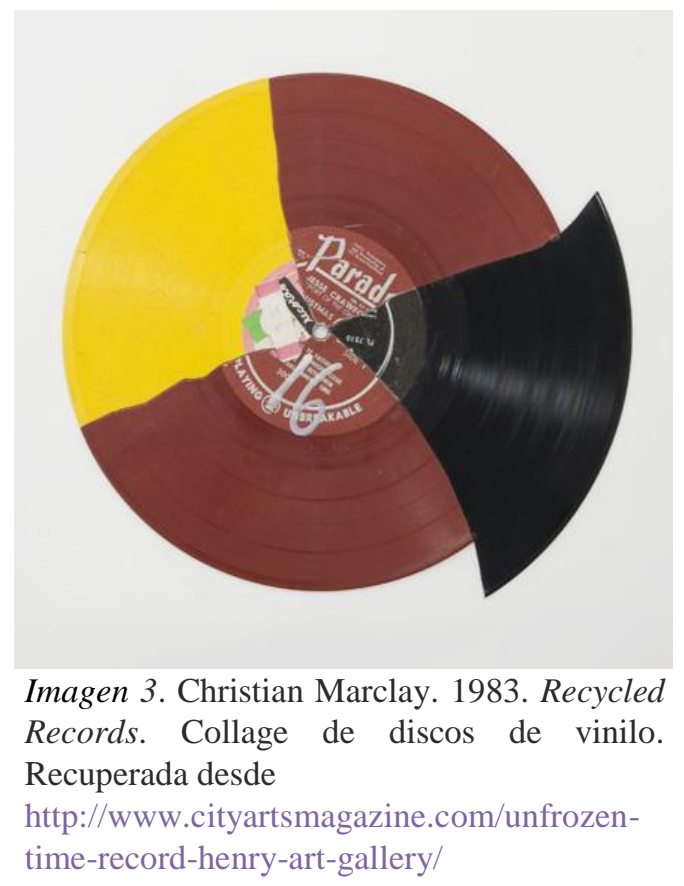




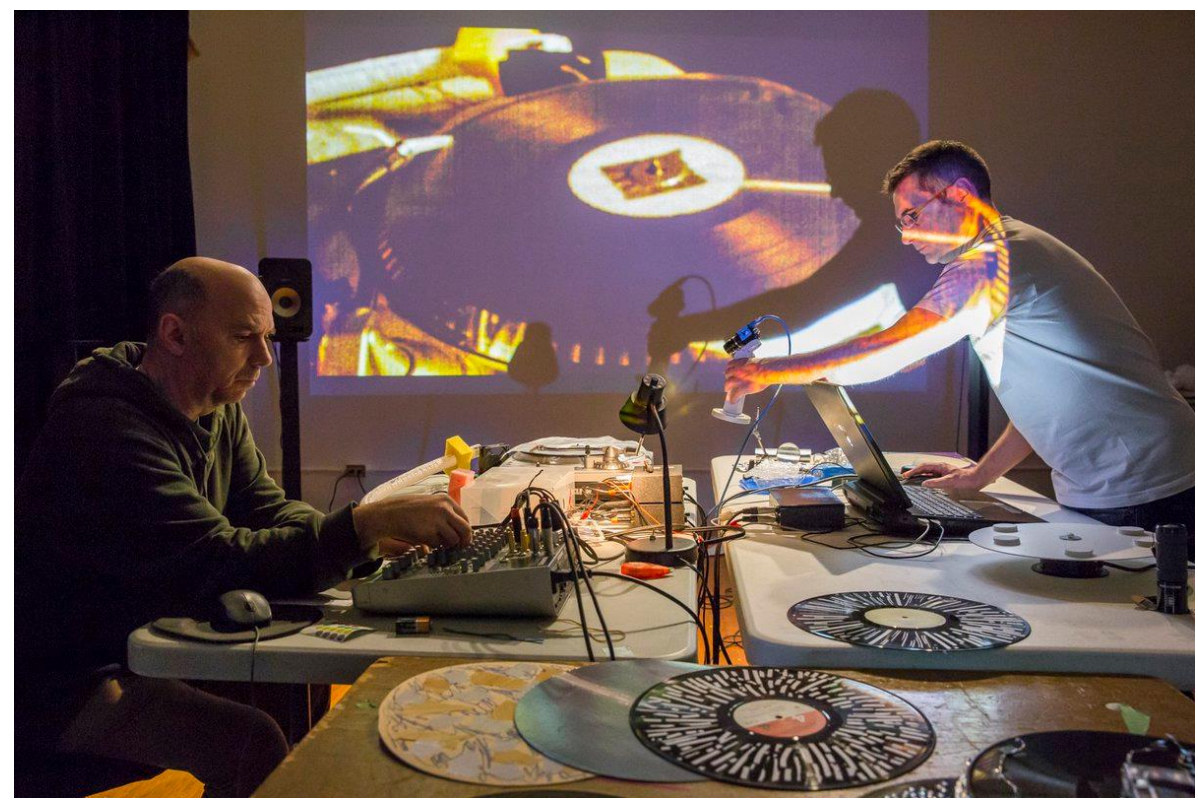

Imagen 4. Martin Tetrault; Thierry Guibert. 2017. Live en Avatar. Quebec. Recuperada desde http://avatarquebec.org/fr/projets/le-disque-thierry-guibert-andmartin-tetreault/\#

\section{Proceso}

También podemos entender el ruido como una forma específica $\mathrm{y}$ determinada de operar del arte, sin su componente de oposición, el error es entendido como parte procesal de la elaboración del objeto artístico. Los accidentes propios del desarrollo de cualquier proceso de trabajo son a menudo un recurso que evidencia manipulación, ejecución, acción, etc. Uno de los ejemplos evidentes que nos sirve de argumentación son las míticas serigrafías de Andy Warhol. La importancia de estas imágenes reside en el hecho de que fueran objetos, personajes, escenas cotidianas, populares, propias de la escena pop y que, al ser impresas, podían ser repetidas mecánicamente hasta el infinito. Sin embargo, hay que tener en cuenta que el azar también tiene un papel decisivo en la imagen final, este nuevo sistema de reproducción determinará resultados accidentales imprevisibles, propios de la ejecución técnica de la herramienta empleada. El hecho de que se disponga de un exceso de tinta en el momento de estampación podrá tener como consecuencia que se produzcan unas impresiones más o menos 
borrosas, si la propia pantalla serigráfica se ensucia y se tapan algunos poros, las imágenes pierden fuerza y color, apareciendo más claras y desdibujadas. El estado en que se encuentre la rasqueta puede también influir en el resultado, puede estar deteriorada después de haber sido utilizada muchas veces, de manera que produzca un tipo de trazo irregular. El abuso de una ejecución rápida propicia imprecisiones que determinarán finalmente un estilo "Warhol" que conducirá a una marca propia del autor.

¿Qué hubiera pensado y escrito Walter Benjamin sobre Andy Warhol si su vida no terminara el día 25 de septiembre de 1940 en Portbou? Él, que había escrito sobre los efectos de la reproductibilidad técnica sobre el aura de las imágenes. Él, que imaginó en la encrucijada de la modernidad otras modernidades. Él, que supo utilizar las herramientas metodológicas de algunas de las vanguardias para lanzar su penetrante mirada sobre la sociedad europea de entreguerras, desmontando los artificios inicuos de la instrumentalización política de las imágenes. ¿Cuántos diálogos imaginarios podríamos hacer entre Benjamin y Warhol? De la queda a la banalización del aura, el arte tuvo que enfrentarse a los artistas que admitían, e incluso buscaban, elementos artísticos en los márgenes del error.

En 1926, en la gran obra "definitivamente inacabada" de Marcel Duchamp, La Mariée mise à nu par ses célibataires, même (Le Grand Verre), y después de un largo proceso de producción entre 1915 y 1925, los cristales de los dos paneles se rompen. El cristal roto es la huella del azar, la marca de una lógica que escapa al control del artista. De nuevo nos encontramos frente a un acto explícito de admitir los errores como son, elementos del acaso que terminan por hacer parte estructurante de la obra. Algo similar queda tajante en una conocida fotografía de Man Ray, de 1920, intitulada Dust Breeding: el polvo como residuo significante que se había acumulado en la superficie del Grand Verre. Duchamp dejaría un segmento de esta obra con polvo, la parte de los conos, de modo permanente.

Haciendo un salto en el tiempo encontramos otra interesante pieza resultado de un error procesal, y lo encontramos en el ámbito virtual de la red de internet de los incipientes noventa, durante la gestación de lo que más tarde se conocerá por net-art. Estamos hablando de wwwwwwwww.jodi.org, de la pareja holandesa Jodi. Este trabajo del año 1995 está considerado como una de las primeras obras de net.art de la historia. Lo primero que nos aparece son unas misteriosas líneas de código representadas mediante una sintaxis propia de los primeros ordenadores, una serie de incomprensible código verde sobre fondo negro. El sentido de este experimento está oculto por su propio proceso de construcción con código html. El objetivo era 
realmente mostrar un dibujo de ascii-art mediante los planos de una bomba atómica. Un error en la colocación de una etiqueta fue la que generó su formalización final. Esta pieza sólo puede tener cierta lógica cuando pasamos a examinar (por casualidad o por algún artículo que nos lo explica) el código fuente de la página. Entendemos pues que en, tal y como nos dice Rachel Greene: "... lo que normalmente se oculta en una página web, la programación, pasa a formar parte del contenido visible en una sopa alfanumérica tan vasta que a menudo sorprender hasta a los más expertos informáticos" (Greene, 2000). Quedamos desconcertados viendo el conjunto de símbolos agrupados sin un aparente sentido, un error de código que conforma una radical propuesta artística. El código como noción estructural de un sistema de construcción de significado y recepción cultural.

Non erratum. El fallo, el equívoco, sin correcciones, sin enmiendas. La obra se construye in lapsus, en la hendidura del proceso, y arrastra con ella la mirada desconcertada del espectador. Al dejar evidente el error pone también ha descubierto el proceso de hallazgo de los defectos que el espectador irremediablemente hace.

Interferencias. Otra consecuencia de la comunicación relacionada directamente con el accidente son las interferencias que ella misma genera. La interferencia es sinónimo del desajuste entre los agentes que se comunican, en el campo de la experimentación artística siempre han estado presentes y valoradas como recurso para su experimentación. Un signo claro de nuestros tiempos es el evento de la comunicación a través de las redes sociales y la mensajería instantánea. La globalización de la inmediatez en la comunicación nos aporta un escenario de interés para su análisis, afectando de plano a la visualidad. Éste actualmente ha recibido un impacto que genera un nuevo paradigma, su compresión. Para ser difundida de manera rápida e inmediata se comprime, con su correspondiente pérdida de definición, deviene pobre.

Parafraseando a Hito Steyerl, en su ya popular artículo del año 2009 In Defense of the Poor Image, podemos aseverar que, dentro de los diferentes formatos de archivo que cita como imágenes pobres, debemos incluir los GIF. La imagen pobre también es GIF, ya que, a pesar de su revitalización y actualidad, son producto de la reducción, compresión, de mezclar, fusionar, derivar, filtrar, alterar e, incluso, del superado ejercicio de cortar y pegar. La limitación de este tipo de imágenes y animaciones en 256 colores hace que las de mayor calidad deban adaptarse y reducir su resolución. Asimismo, 
parte de su éxito debe buscarse por ser soportadas por multitud de navegadores y aplicaciones.

El uso de las imágenes con pérdida de materia es fácilmente asociado a una manera de relacionarse con la tecnología, una posición ética, estética e ideológica, como dice David Casacuberta en "El lowtech hispano": "Podríamos decir que el low-tech, en el fondo, es un estado mental. No es necesario que todo el equipo con el que trabajamos lo hayamos sacado de la basura. Es más la forma en que nos relacionamos estética e ideológicamente con la tecnología" (Casacuberta, 2004). Una consecuencia directa de la manipulación de las imágenes digitales puede derivar en un error de sistema, si hacemos un mal uso físico de un soporte informático, o forzamos un programa que procese información muy diferente a la que es capaz de entender obtenemos resultados sorprendentes. Tumblr y Flickr son una fuente inagotable de este tipo de uso de la imagen, funcionan como grandes repositorios etiquetados que nos adentran en un gran vertedero público en el que se presenta Internet, "el que todo desaparece y nunca logra alcanzar el nivel de atención pública que uno esperaba obtener" (Groys, 2014, p. 134).

Pero es importante ver que ante tanto despliegue tecnológico que ocupa nuestras vidas, en el arte, esta constatación que va en aumento refuerza el discurso del autor. "El arte no puede reducirse a una serie de destrezas técnicas. Es por eso que hoy vemos la reemergencia del discurso sobre el arte como una forma de conocimiento, un discurso que se vuelve inevitable cuando se enseña arte" (Groys, 2014, p. 104). La tecnología ya es asequible para la gran mayoría, hoy podemos tener fácilmente un equipo con el que producir un proyecto audiovisual de alta calidad, las estaciones de trabajo son cada vez más potentes y a precios razonables. Al mismo tiempo el panorama del software corre la misma suerte y una gran red de cursos presenciales y on-line están disponibles sin grandes desembolsos. Todo ello conlleva que la imagen y su producción esté a la orden del día y, por este mismo motivo, su manipulación no tendrá ningún sentido si no definimos qué es lo que queremos decir con ella. Ya no nos importa tanto el uso y su manipulación sino el discurso con el que vestimos la imagen.

Las redes sociales son el paradigma en el que hemos pasado de ser usuarios de las grandes compañías tecnológicas a trabajar para ellas. Como ejemplo está el caso del uso de los códigos captcha que nos adentra en el complejo mundo de los registros y contraseñas, en el que a través de un simulacro imagen-error, se nos identifica como una no-máquina procesal, es decir humanos. La identificación de la presencia humana es identificada por ser capaz de descifrar un texto confuso, producto de un error tipográfico. El 
uso de captcha sirve a las compañías para poder identificar partes de las imágenes borrosas e indefinidas que realizan las cámaras monitorizadas usadas por ejemplo para GoogleMaps. De esta manera nos convertimos en colaboradores sin sueldo de estas, cada vez más, poderosas compañías de la virtualidad, empresas del abismo de la cerodimensionalidad.

Recordando a Antoni Muntadas en la entrevista del año 2012 de la mítica y aún vigente serie de TVE, Metrópolis, nos explicaba de manera elocuente: "Un proyecto define el medio que utiliza, nunca comienzo un proyecto sabiendo el medio que utilizaré" (Muntadas, 2012). Anteponer la selección de la tecnología a utilizar en un proyecto artístico parece no ser su método. Estas palabras de Muntadas son realmente válidas para poder dar contexto al mundo de las imágenes manipuladas. Conscientes pues de que las propuestas artísticas conviven en una realidad de imágenes low-res, nos damos cuenta de que este orden que marca el quehacer de Muntadas pierde su original sentido, la producción de la imagen no es inocente. Por ello, ya nos es igual iniciar un trabajo seleccionando su tecnología o no. La mayoría de las tecnologías actuales determinan los discursos del arte. Podríamos afirmar que el producto y la manera en que digerimos las imágenes está en continuo movimiento y evolución.

Por último, podríamos decir que se trata de un planteamiento suficientemente interesante como para animar una vez más el desarrollo del arte a nuevas exploraciones, que no son simplemente técnicas, sino que implican otra forma de entender la relación con la máquina desde un sentido de originalidad, pedagogía e incluso espiritualidad.

\section{Saturación}

Finalmente, proponemos la concepción de ruido como metáfora de la complejidad de nuestra cotidianidad. Se plasma la sobresaturación de información por parte de los mass-media y el aprendizaje de lenguajes simultáneos. Según el teórico musical y crítico de arte danés Torben Sangild en su libro "The aesthetics of Noise" el ruido tiene una relación directa con la objetividad y la complejidad. "As we have seen above, noise is for instance not always aggressive and loud. Still, there are some common features: noise tends to abandon subjectivity, individuality, rationality, homogeneity and control in favor of the objectively irrational, the pre- or non-subjective sublime, something unstable and complex" (Sangild, 1996).

Hablar de complejidad nos retrotrae a las investigaciones iniciadas a partir de la segunda mitad del siglo XX, cuando las investigaciones 
científicas empiezan a hacer tambalear los cimientos sobre los que la misma ciencia se asentaba para controlar la realidad que rodea al hombre.

A principios del siglo XX la ciencia cuestionaba la causalidad determinista con el azar del indeterminismo y el arte relativizaba la estética académica utilizando "el anti-arte". La búsqueda del negativo del "anti" ha llevado tanto al arte como a la ciencia actual a buscar registros de los estados o procesos de lo que no es observable, como el inframince que Duchamp definió como todo lo que no es medible y "escapa a nuestras definiciones científicas" (Ramírez, 1993, p. 193).

En los tiempos que vivimos el método científico ya no nos resulta del todo útil, nos ha resultado positivo cuando la realidad era fácilmente medible con fórmulas matemáticas, pero si la complejidad aparece, o si no se nos permite descomponerla para entenderla, o si no se nos presenta un modelo, entonces no nos queda otro remedio que obviar los principios científicos y aceptar la hipótesis, es decir, la comunicabilidad de complejidades ininteligibles. Esta comunicabilidad la derivaremos por el canal del arte o, en el caso extremo, utilizamos el conocimiento divino: "Sólo hay tres formas fundamentales de Conocimiento: el científico, el artístico y el revelado. Todo Conocimiento real es la superposición ponderada de las tres formas" (Wagensberg, 1985, p. 163).

El posicionamiento del científico y filósofo Ilya Prigogine (1917-2003) fue rompedor respecto a la tradición newtoniana y sus estudios como precursor de las teorías del caos.

[...] aún estamos inmersos en el proceso de reconceptualización de la física y todavía no sabemos adónde nos llevará. Pero sin duda se abre con él un nuevo capítulo del diálogo entre el hombre y la naturaleza. $\mathrm{Y}$ es significativo que éste se haya iniciado en un marco que, a partir de la explosión demográfica (y de otros procesos sociales, como el auge experimentado por las técnicas informáticas), nos llevará tarde o temprano al desmonoramiento de los conceptos a veces simplistas con los que se pretendía describir las sociedades humanas. (Prigogine, 2004, p. 18)

Junto con él, vemos como científicos de diversas disciplinas se ponen de acuerdo para hablar de la existencia de estas nuevas leyes en la naturaleza, que incluyen la posibilidad de la innovación. Según Prigogine, es el devenir abierto a la probabilidad, es decir, a las reglas del caos, lo que viene a significar que estamos ante un universo abierto, en expansión y, por tanto, de creciente complejidad. 
En su momento, también nos lo advirtió McLuhan cuando nos habla de un universo en el que el Dios mecanicista está muerto:

\begin{abstract}
Mantenga en circulación el rumor de que DIOS ESTÁ VIVO. El Dios newtoniano -el Dios que creó un universo semejante a un reloj, le dio cuerda y se retiró- ha muerto hace mucho tiempo. Eso es lo que quiso decir Nietzsche y ése es el Dios del cual se habla.

Quien busque en torno a sí una imagen simulada de la divinidad de tipo newtoniano, bien podría sentirse defraudado. La frase "Dios ha muerto" se aplica adecuada, correcta, válidamente, al universo newtoniano, que ha muerto. La regla fundamental de ese universo, sobre la cual está construida una parte tan Importante de nuestro mundo occidental, se ha esfumado. (McLuhan, 1998, p. 46)
\end{abstract}

En el nuevo paradigma pasamos a hablar a partir de un nuevo lenguaje definido a partir de nuevos conceptos como "procesos irreversibles e inestables", "teoría de sistemas dinámicos", "teoría de la complejidad", "dinámica fractal", "la auto-organización ","lectura y narrativa no lineal ", todo para sustituir la visión unidireccional y mecanicista del universo por una visión de naturaleza probabilística, más dinámica, en constante proceso de crecimiento e interdependencia que conformará lo que ahora entendemos como complejidad. Toda una serie de conceptos para una nueva realidad enfrentada con el mundo mecánico pautado por Newton, tal como nos cuenta el profesor y matemático Ian Stewart:

La revolución del pensamiento científico que culminó con Newton nos llevó a una visión del universo como un engranaje gigantesco, que funcionaba como un mecanismo de relojería, una frase que todavía se usa para expresar fiabilidad y la precisión mecánica absolutas. (Stewart, 2000, p. 23)

Sinónimos del nuevo paradigma del conocimiento son la inestabilidad y el caos. Según Prigogine, la ley fundamental del universo que llega a toda la creación, incluyendo el arte concebido con las características de las cosas vivas, los procesos vitales, así como con sus problemas de complejidad organizada. Hoy en día ya se sabe que la mirada mecánica entendía las fluctuaciones, el azar o la irreversibilidad como excepciones, eran meros artefactos. Los procesos irreversibles, los modelos considerados por la física clásica nos parecen corresponderse únicamente a situaciones límite que podemos crear artificialmente. 
Podríamos afirmar que el caos, la inestabilidad y el azar son los elementos constitutivos del nuevo arte de la complejidad producido en sistemas dinámicos que, desde antes de la irrupción de las nuevas tecnologías, está cambiando sus procesos creativos e inventando el futuro, al desplazar los centros vitales de la práctica artística a otros nuevos. Esto implica ir de los estados a los procesos, de los productos a los organismos y las relaciones, de lo cuantitativo a lo cualitativo, de los campos cerrados a los polisémicos, de las formas únicas a las formas múltiples, de lo determinado a lo indeterminado, de lo inmutable a lo mutable, de lo real a lo virtual, de lo contemplativo a lo interactivo (Solar, 2010).

Las acumulativas casi Diogenèticas instalaciones del artista estadounidense Jason Rhoades son un buen ejemplo de esta concepción del error-saturación. Los trabajos de Rhoades crean sistemas de relaciones entre la realidad, la experiencia y los medios de comunicación como metáfora de la complejidad de nuestra cotidianidad. Rhoades reacciona a los miles de impresiones que toda persona percibe cada día. Mostrar este caos visual al que es sometido el individuo, y cómo operan con la misma obligatoriedad o voluntariedad que las propuestas de la cultura diaria de los medios. Sus instalaciones ofrecen una simultaneidad de lecturas que se refieren a la literalidad de las cosas y/o su conversión en metáforas y metonimias. El flujo define esta acumulación de narrativas en el mismo objeto. En sus laberínticas instalaciones que funcionan como expresiones comunitarias del culto al consumo, "se otorga al espectador una agradable experiencia regresiva que en última instancia hace muy poco que pueda describirse como emancipador. En realidad, no hay nada de lo que asombrarse, ya que el abrumador registro de la obra de Rhoades es el humor nihilista" (CoulterSmith, 2009, p. 66).

Thomas Hirschhorn es otro artista que incorpora en sus ambientes/instalaciones una constelación de objetos y materiales diversos en una articulación acumulativa y repetitiva, en algunos casos comparable a la estética noise. En Crystal of Resistance, obra de gran formato para la Bienal de Venecia de 2011, el visitante accede, en fila, al interior de una especie de cueva apocalíptica. Los dibujos preparatorios que hizo Hirschhorn (en los que hay una referencia al Étant Donnés de Duchamp) evidencian el cristal, y todo su carácter de fábula, en torno al fragmento: los despojos de belleza contrastan con los fragmentos de violencia de lo real (fotografías y vídeos) y la violencia de las yuxtaposiciones, los destrozos, o los objetos inmovilizados con cinta de embalaje (un elemento habitual en sus obras). 


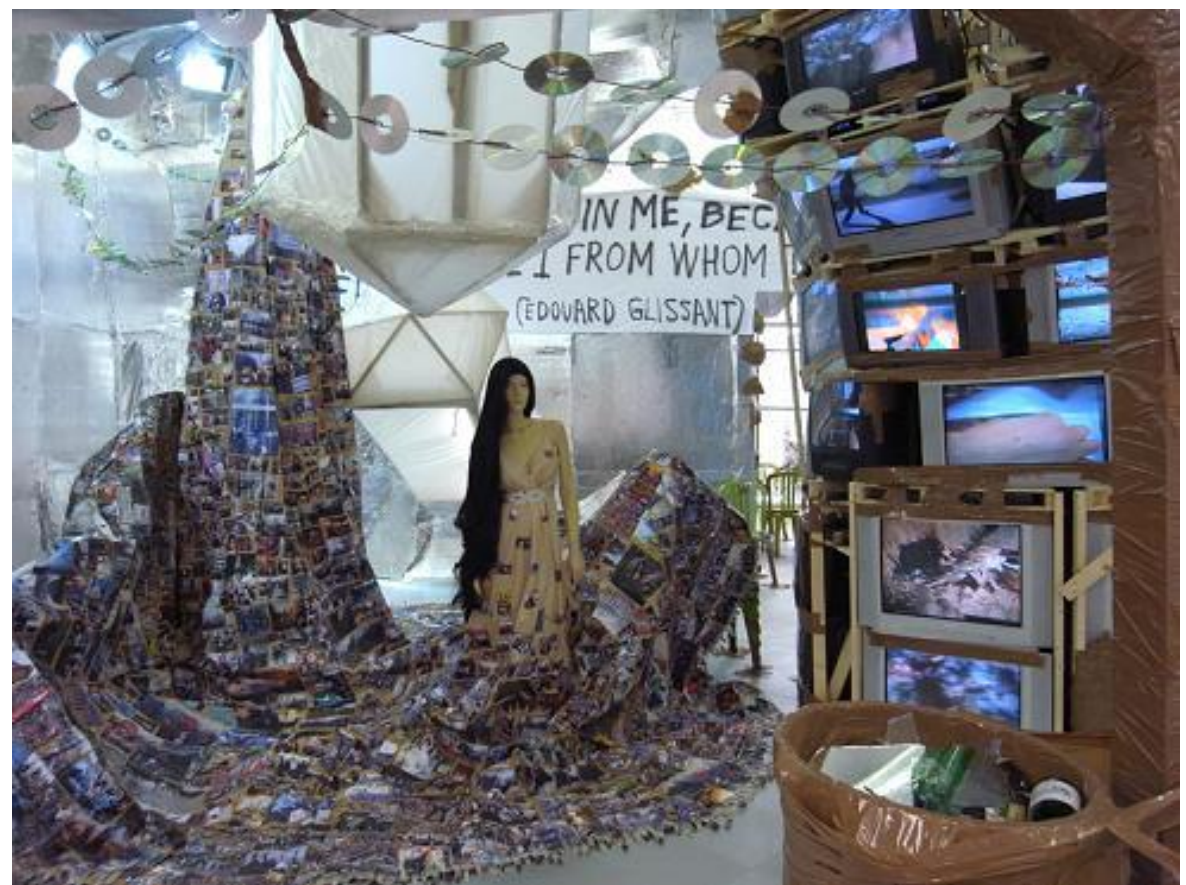

Imagen 5. Thomas Hirschhorn. 2011. Crystal of Resistance. Proyecto para la Bienal de Venecia. Recuperada desde

http://ericmainville.com/wp-content/uploads/2011/06/01.jpg

Sus instalaciones y piezas colaborativas juegan con las nociones de acumulación y saturación en un contexto capitalista de mediación, y ofrecen modos de resistencia, modelos alternativos para relacionarse con el espectador y los participantes (véase el ejemplo de su reciente proyecto Gramsci Monument, en el espacio público de las Forest Houses en el barrio de Morrisania del Bronx, Nueva Iorque). Una manera de pensar el supuesto orden capitalista, que no conduce sino a un desorden insípido, y las consecuencias perversas de la cultura de lo desechable bajo el signo del (ilusorio) capital renovable.

Cinco años después de la experiencia que más ha contribuido para crear un estilo sin estilo, una actitud musical más que nada, de los Velvet Underground, una alucinación sónica sin muchos precedentes, Lou Reed estrenaba, en 1975, su sexto álbum en solitario, Metal Machine Music. Una verdadera exaltación al ruido, requiriendo para ello la distorsión del feedback como "herramienta" musical. Durante sus 64 minutos nos enfrentamos a una a-sinfonía electrónica de total trance ruidístico. En una 
página de la revista Cream, aparecía escrito únicamente la palabra NO, en mayúsculas, repetidas veces. Tal fue la respuesta, en su momento, de una parte de la crítica.

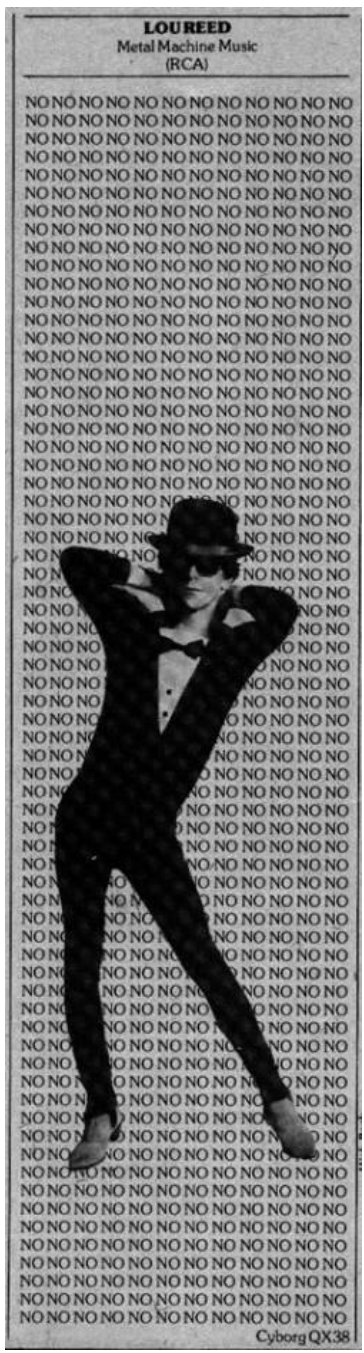

Imagen 6. Imagen de la publicación de la crítica acerca del álbum de Lou Reed Metal Machine Music en la revista Cream. 1975. Recuperada desde

https://rockcritics.files.wordpress.com/ 2013/11/metalmachinemusic.jpg 
Los Sex Pistols se separaron en 1978, año en que el movimiento punk cobró vida en Japón. Se centró en Tokio con la escena Rockers y en Osaka con el movimiento Kansai No Wave (Matsumura, 2014), que incorporó bandas de Osaka, Kobe, Kyoto y otros lugares de la región de Kansai. Los fundadores de la escena del ruido japonés comenzaron como punks, y se desarrolló de manera muy intensa por muchas ininterrumpidas generaciones de grupos de estética corrosiva y masiva. De entre todos podemos destacar al máximo representante del puro ataque de la distorsión y saturación tímbrica, Merzbow (Masami Akita). El nombre Merzbow proviene del Merzbau de Kurt Schwitters, reflejando, de esta manera, su influencia dadá y la estética del arte basura. Merzbow es considerado como uno de los padres y máximo exponente del Noise, la Extreme Noise. Utiliza básicamente pedales de distorsión en serie y en paralelo, samplers y algunos artefactos creados por él mismo. Soportar sus temas de una duración media de 10 minutos es todo un reto, ya que a menudo son composiciones libres sin ninguna estructura interna que combinan elementos de terror digital y dron con torturas acústicas. Recibimos una masa sonora como fenómeno físico que las técnicas provocan, sirven de discurso a la hora de expresar contenidos no sólo sobre el soporte mismo, sino también como transformación del mundo post industrial e interconectado.

Los teóricos del totalitarismo: todos ellos, indistintamente, explicaron que es preciso prohibir los ruidos subversivos, porque anuncian exigencias de autonomía cultural, reivindicaciones de diferencias o de marginalidad: la preocupación por el mantenimiento del tonalismo, la primacía de la melodía, la desconfianza con respecto a los lenguajes, los códigos, los instrumentos nuevos, el rechazo de lo anormal, se encontraron en todos esos regímenes, traducciones explícitas de la importancia política de la represión (Attali, 1995, p. 17).

Queda claro que el ruido es prescindible, hasta violentamente evitable, por lo que las dictaduras han soñado en eliminarlo. Incluso en la época del imperialismo electrónico, generador de tanta basura. Pero por otro lado el ruido libera al oyente del oído filtrado, una respuesta contra-negativa que define una praxis muy experimental. En ese sentido lo encontramos, en algunos casos, muy cercano al silencio (por extraño que pueda parecer). Los dos pueden determinar un acto de obstinación, de tenaz impertinencia. Basta pensar en la pieza 4'33", de Cage, donde silencio y ruido se envuelven mutuamente, dos extremos que resisten a las pautas de la normalidad o la exponen como algo insoportable. El ruido es ese "simulacro de muerte" (Attali) que obstruye con intimidación la dinámica de la transmisión, 
trastorna el discurso y lo reemplaza por una atención extraviada, relegada a esferas marginales o todavía no codificadas de lo cultural. El ruido no participa del poder a causa de su condición "impura". Porque es la parte de la comunicación que se pierde, que ha sido relegada a la marginalidad y no conoce del poder más que la limpieza exterminadora que este ejerce midiendo ninguna otra alternativa que la suya misma (lo que instituye otro tipo de ruido, el que mejor fluye en las venas de la sociedad).
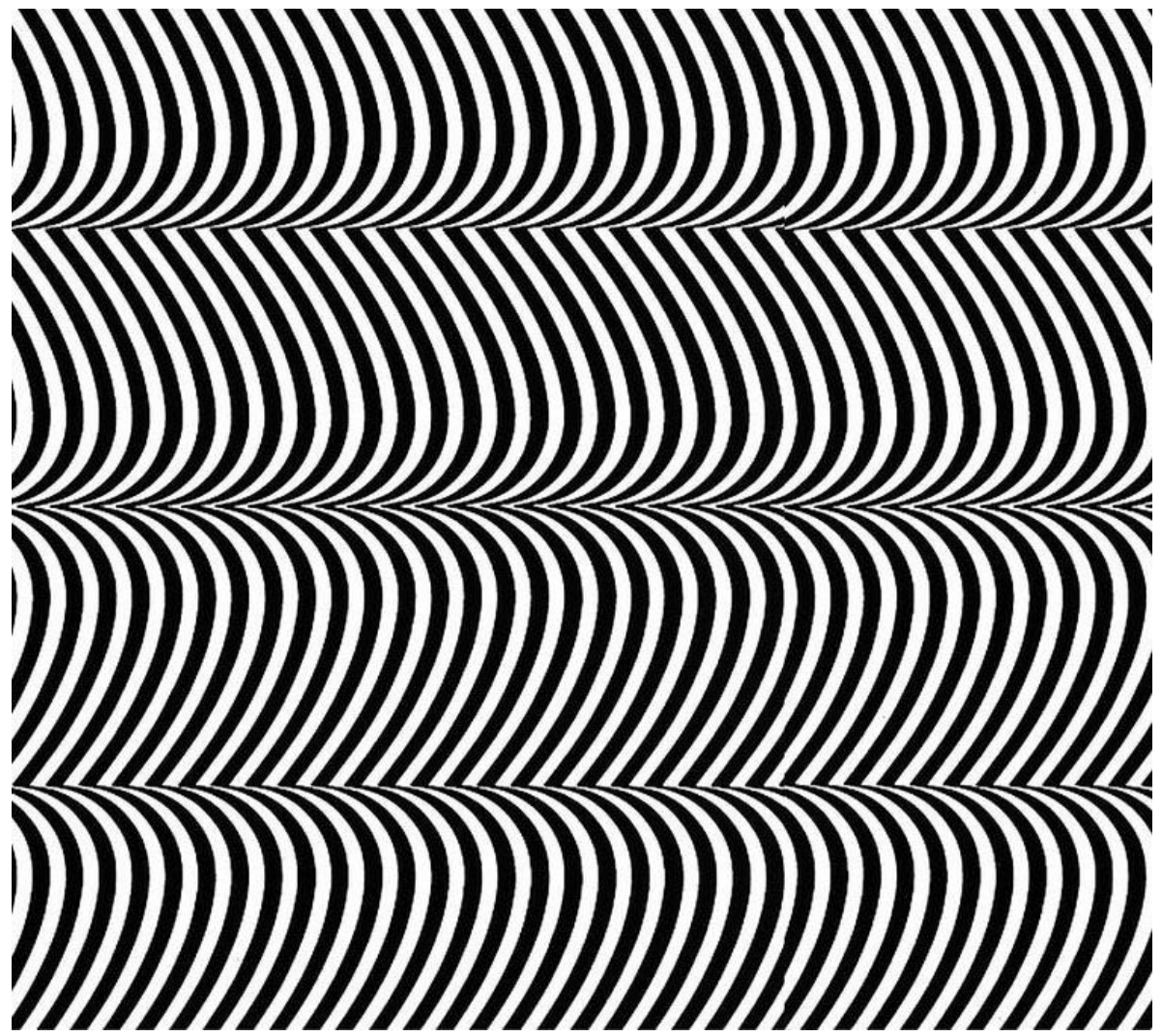

Imagen 7. Merzbow. 1996. Imagen de la cubierta del LP. Pulse Demon. Recuperada desde https://www.discogs.com/es/Merzbow-Pulse-Demon/master/134227

Serendipia. Pero es interesante poder detenerse ante un aspecto también muy explorado, aunque poco reivindicado y es sencillamente la obtención por error de un objetivo no esperado, es decir la serendipia. Este es un amplio método de investigación de múltiples disciplinas a través del cual el ámbito científico ha logrado grandes hitos, cabe destacar el horno de 
microondas, los detectores de humo, los edulcorantes artificiales, las radiografías, etc... Muchas webs divulgativas y muy populares se hacen eco de todos estos avances por casualidad. Pero evitando estas evidencias encuadradas como curiosidades podemos retrotraernos a la determinante exposición para el desarrollo del computer art. Se presentó con el título de "Cybernetic Serendipity: The Computer and the Arts" en el ICA de Londres en 1968 y fue organizada por Jasia Reichardt a partir de la iniciativa del semiótico y especialista en estética de la información Max Bense. Esta determinante exposición ha sido valorada positivamente por la oportunidad de la propuesta, aun así, tal y como nos comenta E. Castaños, el artista Yturralde, "aun reconociendo el enorme despliegue de medios utilizados y la información suministrada al público, pone en cuestión su grado de originalidad y se refiere en términos muy críticos a su carácter galerístico y de propaganda, actitud esta última, por otro lado, propia de unos años en los que el mundo del mercado de arte y la relación de éste con intereses declaradamente económicos y de promoción publicitaria se contemplaba con bastante recelo" (Castaños, 2000, p. 78). Esta muestra presenta, por primera vez, una serie de autores como Charles Csuri, Charles Pask, Frieder Nake, Michael Noll, John Whitney, Edward Ihnatowicz, Computer Technique Group, Kenneth Knowlton, Michael Noll. Aunque, como bien dice Yturralde, en un contexto más propagandístico que de aportación al conocimiento de estas nuevas líneas de trabajo creativo, todos los artistas de la exposición utilizan el ordenador como herramienta fundamental que permite elaborar la obra, "procesarla". Así, esta exposición podría estar generada a partir del cuestionamiento ¿cómo los movimientos caóticos son predecibles a pesar de que siguen leyes formalmente deterministas? En "Cybernetic Serendipity" fueron reunidas un conjunto de obras computacionales que planteaban la experimentación a través de factores indeterminados, la paradoja de la convivencia entre un objeto creado para el cálculo numérico y elementos azarosos, una conformación confusa de nuestra contemporaneidad, una tensión entre el orden y el azar. El mecanicismo decimonónico que creía poder predecir hasta los últimos detalles de todas las leyes de la naturaleza se ha hundido completamente. Vivimos pues en un nuevo determinismo, menos radical, que combina el determinismo con las probabilidades.

\section{No No No... (Conclusiones)}

La patología de la comunicación no es sólo el hecho de la escritura. También existe en la lengua hablada: tartamudeos, lapsus linguae, 
acentos regionales, diacronías y cacofonías. Lo mismo en los medios técnicos de comunicación: ruidos de fondo, caídas de agua, interferencias, parásitos, cortes sincrónicos. Con el conjunto de pensamientos, lo occidental, el ruido de fondo es esencial en la comunicación. (Serres, 1996, p. 45)

¿Qué es lo que queda del ruido, de la interrupción (en sus múltiples modos), de las obstrucciones, de las rupturas, del error? ¿Cómo separar de las patologías de la comunicación, como las llama Serres, la basura, el desecho improductivo y negativo, de una contra-negación activa, de un espacio metodológico experimental y fuera de los parámetros demasiado rígidos de lo institucional? Casi somos llevados a afirmar que la cueva de Hirschhorn es la antítesis alegórica de la cueva platónica. Allí los sentidos viven en exceso, in extremis, pero son necesarios. Es el último lugar donde querríamos estar, porque no es un lugar cómodo. No nos resignamos a ello, pero cuando nos distanciamos seguimos en su interior. Entonces, ¿Qué lugar puede ocupar el error? ¿Qué esencia es esa de la que habla Serres? Somos seres que establecen sus lazos con el mundo a través de complejos sistemas de comunicación (empezando por el habla), pero también sabemos que esos sistemas están sujetos a errores, a interrupciones, a extravíos. Los artistas y propuestas artísticas que han hecho parte de estas páginas han tratado de interpretar esas patologías desde una posición desestabilizadora, es decir, creando huecos, espacios negativos que permiten ampliar la reinvención de los lenguajes. Todas estas perspectivas del error aquí presentadas existen al servicio de un enfoque dialógico entre la esencia interruptora y todo lo que le resiste. Por otra parte, presuponen programas de insubordinación a lo instituido o al control disciplinado del proceso estético. En ese sentido se ha tenido en cuenta la diversidad de los planteamientos en distintos ámbitos del arte contemporáneo y de la escena musical experimental.

Queda así evidenciado el inabarcable campo multiforme en el que se nos presenta el error, necesitaríamos pues nuevas aproximaciones e incluso nuevos enfoques desde los que abordar el cuestionamiento de lo preestablecido. Siempre estarán abiertos los caminos donde el error tiene espacio y sentido. A ellos habrá que volver para ser justos e (in)coherentes. 


\section{Referencias}

Attali, J. (1995). Ruidos. Ensayo sobre la economía política de la música. Madrid: Siglo Veintiuno Editores.

Beckett, S. (2001). Rumbo a peor. Barcelona: Editorial Lumen. (Edición bilingüe)

Casacuberta, D. (2004). "El Low-Tech hispano".

http://www.ub.edu/imarte/investigacions/estudis-teorics/davidcasacuberta/el-lowtech-hispano/

Castaños, E. (2000). Los orígenes del arte cibernético en España. Consultado desde http://www.cervantesvirtual.com/obra/losorigenes-del-arte-cibernetico-en-espana-el-seminario-de-generacionautomatica-de-formas-plasticas-del-centro-de-calculo-de-launiversidad-de-madrid-19681973--0/

Coulter-Smith, G. (2009). Deconstruyendo las instalaciones. Madrid: Brumaria.

Formaggio, D. (1976). Arte. Barcelona: Labor.

Greene, R. (2000). "Una historia del arte de internet". Consultado desde https://tacticaspublicas.wordpress.com/2017/02/21/una-historia-delarte-de-internet-rachel-greene/ Original publicado como "WEB WORK A HISTORY OF INTERNET ART" en ARTFORUM International, no 9 May 2000, pp. 162-167, 190.

Groys, B. (2014). Volverse público. Las transformaciones del arte en el ágora contemporánea. Buenos Aires: La Caja negra.

Le Feuvre, L. (Ed.). (2010). Failure. (Documents of Contemporary Art). London: Whitechapel Gallery; Cambridge, Massachusetts: MIT Press.

Matsumura, M. (2014). The Birth of Noise in Japan. Consultado desde http://daily.redbullmusicacademy.com/2014/10/birth-of-noise-injapan-feature

McLuhan, M. (1998). El medio es el masaje. Un inventario de efectos. Barcelona: Paidós Studio.

Muntadas, A. (2012). Programa RTVE. Metrópolis.

http://www.rtve.es/alacarta/videos/metropolis/metropolis-antonimuntadas/1300175/

Prigogine, I. (2004). Tan sólo una ilusión. Una exploración del caos al orden. Barcelona: Tusquets.

Ramírez, J. A. (1993). Duchamp. Amor y muerte. Madrid: Siruela. 
Sangild, T. (1996). "The Aesthetics of Noise". Consultado desde https://archive.org/stream/ruidolibrebibliografia/Sangild_theaesthetics-of-noise_djvu.txt

Serres, M. (1996). La comunicación. Hermes I. Barcelona: Editorial Anthropos.

Solar, M. (2010). "Arte de la complejidad: aleatoriedad, fractalidad, caos". Consultado desde http://forumpoesiaestancial.blogspot.com.es/2010/06/arte-de-lacomplejidad-aleatoriedad_3682.html.

Stewart, I. (2000). ¿Juega Dios a los dados? La nueva matemática del caos. Barcelona: Ed. Crítica.

Wagensberg, J. (1985). Ideas sobre la complejidad del mundo. Barcelona: Tusquets.

Eloi Puig Mestres, Victor Manuel Ornelas Magalháes: Universidad de Barcelona, Universidad de Madeira.

Email address: puigme@ub.edu,vmagal@uma.pt

Web: http://www.eloipuig.com, http://www.v-magal.com

Contact Address: Facultat de Belles Arts. C/ Pau Gargallo 4, Barcelona 08028. Barcelona / Faculdade de Artes e Humanidades. Penteada University Campus , Floor -1, Office 01.63 